\title{
Video processing analysis for the determination and evaluation of the chemotactic response in bacterial populations
}

\author{
Melina Nisenbaum, ${ }^{\mathrm{a}, *}$ Emilio Maldonado, ${ }^{\mathrm{b}}$ Jorge Martínez Arca, Jorge F. González, ${ }^{\mathrm{c}}$ LucíaI. Passoni, \\ Silvia E Murialdo ${ }^{\mathrm{c}}$ \\ a Grupo de Ingeniería Bioquímica, Universidad Nacional de Mar del Plata. CONICET, Facultad de Ingeniería, Juan B Justo 4302, Mar del Plata, Buenos aires, Argentina

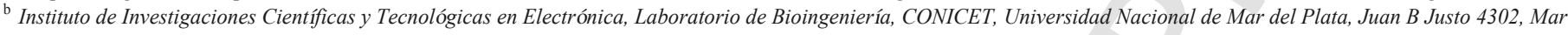 \\ del Plata, Buenos aires, Argentina

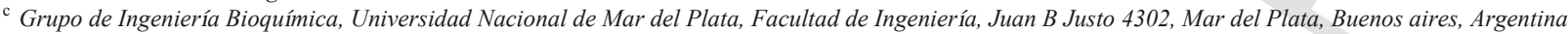

\section{A R T I C L E I N F O}

\section{Article history:}

Received 11 May 2016

Received in revised form 7 June 2016

Accepted 7 June 2016

Available online $\mathrm{xxx}$

Keywords:

Agarose-in plug bridge method

Bacteria

Chemotaxis

Video digital processing

Shannon entropy

Optical microscopy

\section{Introduction}

Chemotaxis is defined as the capacity of certain organisms to sense substance concentration gradients and in turn move towards or away from this gradient (Paul et al., 2006). Bacterial chemotaxis may have a significant impact on the structure and function of bacterial communities (Law and Aitken, 2005). This would allow finding optimal conditions to preserve their species. This behavior also increases pollutant bioavailability, enhances biodegradation rates and may improve microbial inoculants designed just on catabolic potential (Krell et al., 2013). Therefore, in biodegradation processes is very important to design or choose the best method for detecting bacterial chemotactic response towards recalcitrant compounds.

The motion of bacterial populations can be studied by assays that are useful for determining bulk bacterial-transport parameters. These parameters can be used in population-scale chemotactic models (Law and Aitken, 2005) to determine the effect of chemotaxis on the chemoattractants degradation (Bosma et al., 1988; Marx and Aitken, 2000; Pedit et al., 2002). To date, most of reported population-scale chemotaxis assays are primarily qualitative, as the swarm plate assay (Adler, 1966) and the agarose-in-plug method (Yu and Alam, 1997). These methods have considerably utility (Lewus and Ford, 2001; Vladimirov et al., 2008) and are generally used to determine whether chemotaxis occurs or to compare chemotactic responses. Although

\footnotetext{
* Corresponding author at: Juan B Justo 4302, 7600 Mar del Plata, Buenos Aires,
} Argentina.

Email address: melinan@fi.mdp.edu.ar (M. Nisenbaum) they are easy to use, these methods are limited in the accurate control of chemical gradients, low sensitivity or have long analytical times (Jeong et al., 2013). The agarose-in plug assay is a low cost and simple real time assay but prone to false positive responses (Li et al., 2010).

Quantitative chemotaxis assays can measure bacterial accumulation or bacterial density profiles (Law and Aitken, 2005). Quantification of chemotactic motion is necessary to identify chemoeffectors and to determine the bacterial transport parameters used in predictive models of chemotaxis (Law and Aitken, 2005). Direct-viewing assays, where cells migrate on a horizontal surface have particular advantages for quantitative studies (Meyvantsson et al., 2011). Methods that measure bacterial accumulations involve sampling one or more fixed points in an experimental system, as the capillary assay (Adler, 1969, 1973), the fused capillary array assay (Berg and Turner, 1990), a highly sensitive microfluidic assay (Mao et al., 2003), and continuous-flow capillary assay (Law and Aitken, 2005). Methods that determine the bacterial density profile track the motion of a band of bacteria through time, like the defined-gradient system (Dahlquist et al., 1972), the stopped-flow diffusion chamber (Phillips et al., 1994), the diffusion gradient chamber (Emerson et al., 1994), the time lapse capillary assay (Boudko et al., 2003), the densitometry assay (Ortega-Calvo et al., 2003) and other light-scattering methods (Schmidt et al., 1997; Zaval'skii et al., 2003). These methods use concentrations of bacteria typically too high (about $10^{7}$ cells $/ \mathrm{ml}$ and greater) to ignore metabolism of the chemoeffector, since chemoeffectors or chemoattractants are often nutrients that bacteria consume (Law and Aitken, 2005). 
In recent years, most of the chemotaxis reports study the attractant sensing mechanisms of the bacteria (Berg and Tedesco, 1975; Spudich and Koshland, 1975; Rubik and Koshland, 1978; Segall et al., 1986; Jasuja et al., 1999; Cluzel et al., 2000; Gestwicki and Kiessling, 2002; Tu, 2013) or the motility strategies (such as twitching, swarming, swimming, gliding and sliding) (Tsang et al., 1973; Larsen et al., 1974; Taylor and Koshland, 1974; Harwood et al., 1989; Berg, 1993; Thar and Fenchel, 2001; Thar and Kühl, 2003; Lauga and Powers, 2009; and Di Leonardo et al., 2011). Currently, little importance has been given to find new and specific methods of detection and analysis of chemotaxis population responses. Studying the coordinated temporal and spatial movement of bacterial clusters, combined with previous molecular discoveries, might be useful as predicting the strategies of microorganisms in response to fluctuations in the microenvironment.

The aim of the present work was to design a methodology based on video processing to obtain spatial and temporal indicators of bacterial population motility. They might allow the qualitative and quantitative analysis and comparison of the chemotactic phenomenon with a simple and low cost assay as the agarose-in plug bridge method proposed by $\mathrm{Yu}$ and Alam (1997). Entropy is commonly understood as a measure of disorder in different systems under study. In general, the resulting change from formed to free, from ordered to disordered states increases the entropy (Shannon, 1948). In particular, several motile bacteria trying to approach the chemoeffector, do it in an increasingly reduced space available for movement and can collide or interfere with each other along its path, altering the entropy. Therefore, higher prevalence of motile disorders among temporal and spatial areas than control assays, could be seen as chemotactic responses. Consequently, we proposed an entropy function to achieve a descriptor of the level of motile bacteria population within areas of the video frames.

\section{Material and methods}

\subsection{Microbial assay}

A culture of Pseudomonas aeruginosa strain H (Murialdo et al., 2003; Nisenbaum et al., 2013) in the exponential growth phase was used in this study. This culture is chemotactic to LB and hydrocarbons, which was detected in swarm agar plates with speckle laser (Nisenbaum et al., 2013).

The cells were harvested by centrifugation at $3000 \times g$ per $20 \mathrm{~min}$. After that, they were resuspended in motility buffer $(0.1 \mathrm{mM}$ EDTA and $10 \mathrm{mM} \mathrm{PO}_{4} \mathrm{~K}_{3}, \mathrm{pH} 7$ ) and kept at $150 \mathrm{rpm}$ and $30^{\circ} \mathrm{C}$ for $24 \mathrm{~h}$ with no addition of carbon source.
The agarose-in plug assay was conducted by placing a drop of agar 1\%(w/v) (plug) in a chemotaxis chamber (Yu and Alam, 1997). The agar was previously dissolved in motility buffer and contained one of the following attractants: 1\% $(w / v)$ LB (broth Luria-Bertani, positive plug), or $1 \%(v / v)$ glycerol or hydrocarbon ( $n$-hexadecane, 1-decene, 1-dodecene, 1-octene, 1-nonene, kerosene). A negative control assay for bacterial chemotaxis was conducted with an agar plug without attractant. The chemotaxis chamber was made with two plastic strips glued to a slide. The bacterial suspension with a cell concentration of $10^{8} \mathrm{UFC} / \mathrm{ml}\left(\mathrm{OD}_{600}=0.2\right)$ for positive plug and $10^{9} \mathrm{UFC} /$ $\mathrm{ml}\left(\mathrm{OD}_{600}=0.9\right)$ for hydrocarbons and negative plug, was incorporated into the chamber. Bacterial motility in the surrounding areas of the plug was observed with an optical microscope (Olympus BH2) at $600 \times$ magnification, equipped with a phase contrast filter. The assays were carried out in triplicate.

\subsection{Image acquisition and processing}

Twenty second-videos were recorded after the beginning of each assay at 1,3 and 5 min, using a digital camera (Cyber-Shot Sony DSCW5) attached to the optical microscope with an optical zoom of 1,7, in the $\mathrm{B} \& \mathrm{~W}$ mode, at 30 frames per second. Thus, 600 images were obtained and divided in five sequential sub series of 120 events each.

Captured images in MPEG format, originally in RGB (Red, Green, Blue) color space were converted to the HIS space (Hue, Intensity and Saturation). Afterwards the intensity component of each image was selected and rescaled in 256 levels ( 8 bits definition) to improve the image contrast. To analyze the time series intensity of each pixel, the Shannon Entropy (Shannon, 1948) was used as a descriptor. Each of five samples with 120 frames each were used to computed to obtain an entropy value and the final entropy that characterize the pixel was estimated as the median of the five processed values. The final value of the entropy is used to assemble the pseudolored image of the assay.

In Fig. 1 a diagram of the whole process is shown. Beginning from the video acquisition step of spatial bacterial clusters (Fig 1 A), followed by the identification of the temporal video image sequences (Fig $1 \mathrm{~B}$ ). The processing of the temporal series of intensities of each pixel (Fig $1 \mathrm{C}$ ) is follow by the computation of the entropy for each pixel (Section 2.3), and the pseudo colored processed image obtained (Fig $1 \mathrm{D})$, that indicates with hottest colors those regions of highest bacteria motilities.

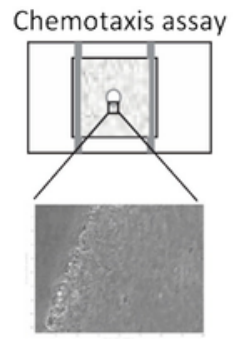

A. Videotapping

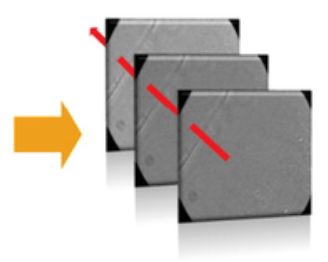

B. Temporal video image sequences

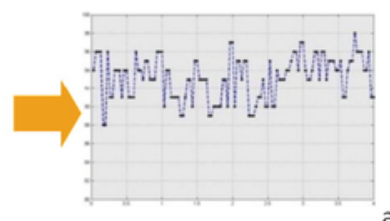

C. Pixel intensity time series

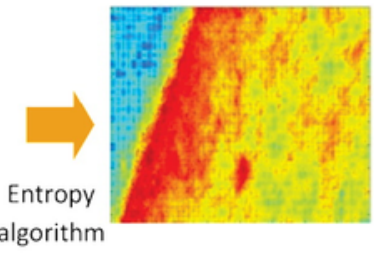

D. Processed Image

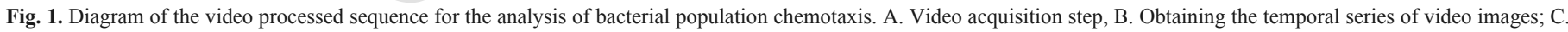

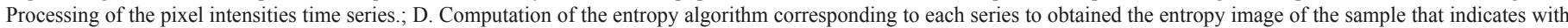
hottest colors those regions of highest bacteria motilities. (For interpretation of the references to color in this figure legend, the reader is referred to the web version of this article.) 


\subsection{Selection of descriptors}

In the agarose-in plug assay there is a concentration gradient generated by the diffusion of the compound present in the plug towards the cell suspension. Chemotactic bacteria swim towards the plug and pile up surround it. To achieve a descriptor of the level of motile bacteria population within areas of the frames, it was proposed a measurement of the intensity variation of each pixel in the time series. The Entropy function was selected as a possible indicator considering intensity variation as a random variable.

Alive and motile bacteria were the only moving elements in the assays, thus, they were responsible for the intensity variability of each pixel. The more uniform the probability distribution of the variable, the higher the estimation of the presence of motile bacteria at the location.

\subsubsection{Theory and calculation}

Entropy (Shannon, 1948) is a measure of dispersion, uncertainty, disorder and diversification. The concept of Shannon's entropy may be applied to anything that may be described using a probabilistic distribution, considering it as a measure of the degree of order of a complex signal.

Considering the intensity levels of the microscopy images as discrete sets $(0 \ldots 255)$ we can address the discrete form of entropy $E(x)$ given as (Shannon, 1948):

$$
E(x)=-\sum_{k=0}^{255} p\left(x_{k}\right) \log \left[p\left(x_{k}\right)\right]
$$
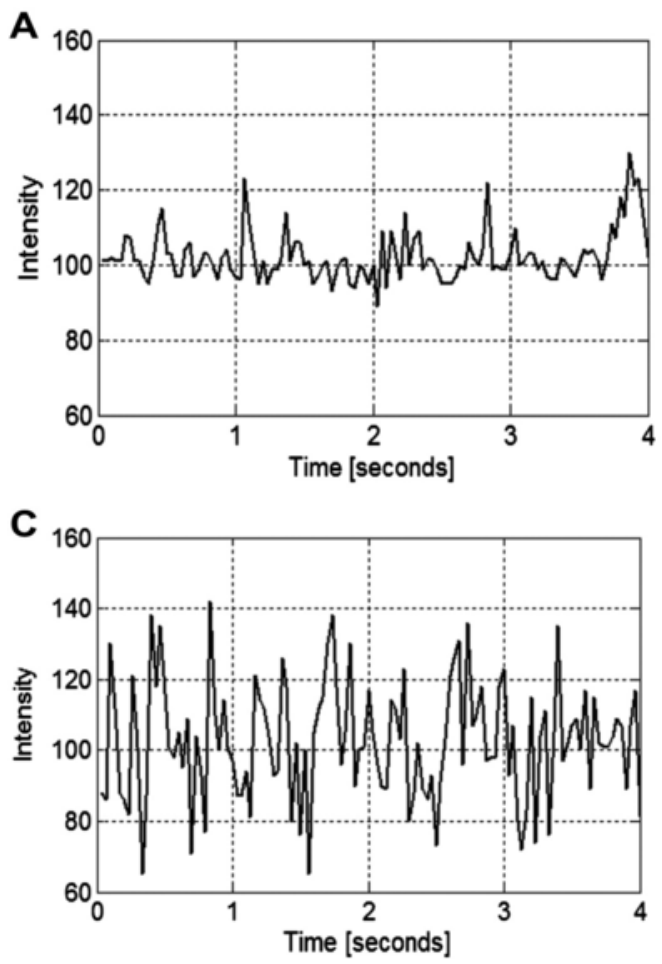

where $k$ denotes a discrete data interval $(0 \ldots 255), x_{k}$ is an outcome corresponding to interval $k$ (the intensity at $k$ level); and $p\left(x_{k}\right)$ is the probability $x_{k}$ of the intensity at $k$ level. The probability $p\left(x_{k}\right)$ is based on the empirical frequency of $x$ values.

Kapur (1989) points out with extensive documentation the following fields where Shannon entropy has been used to characterize various phenomena, as the analysis of time series concerning geographical, astronomical, meteorological or rainfall data, and biological, ecological and medical models.

In genetics Shannon Entropy has been used to measure anatomical gene expression patterns (Fuhrman et al., 2000). Unchanging patterns (such as genes with no diversity of expression levels) have zero entropy, or zero information. On the other hand, genes that are expressed at more than one level have entropy greater than zero, and therefore contain information about phenotypic change. Genes with highest entropy are the biggest participants in a disease process.

In microbiology it has been used to assess the diversity including hydrocarbon degraders (Beck and Schwanghart, 2010). Shannon index has been studied in ecology of higher organisms to measure the diversity of ecosystems, in this cases the use of Shannon equation allows measuring the probability that an individual belongs to the species. Entropy would be useful to assess diversity, providing a measure of system complexity.

Entropy measures the amount of information contained in a distribution; that is, the amount of uncertainty or information concerning the performance of an experiment. In this particular case, the Shannon entropy value addresses the diversity of intensity values of the pixel time series.

As an example Fig. 2 shows time series of pixel intensities and its entropy computed values that correspond to two regions with different bacteria motility of the sample videos obtained in this study. In

B
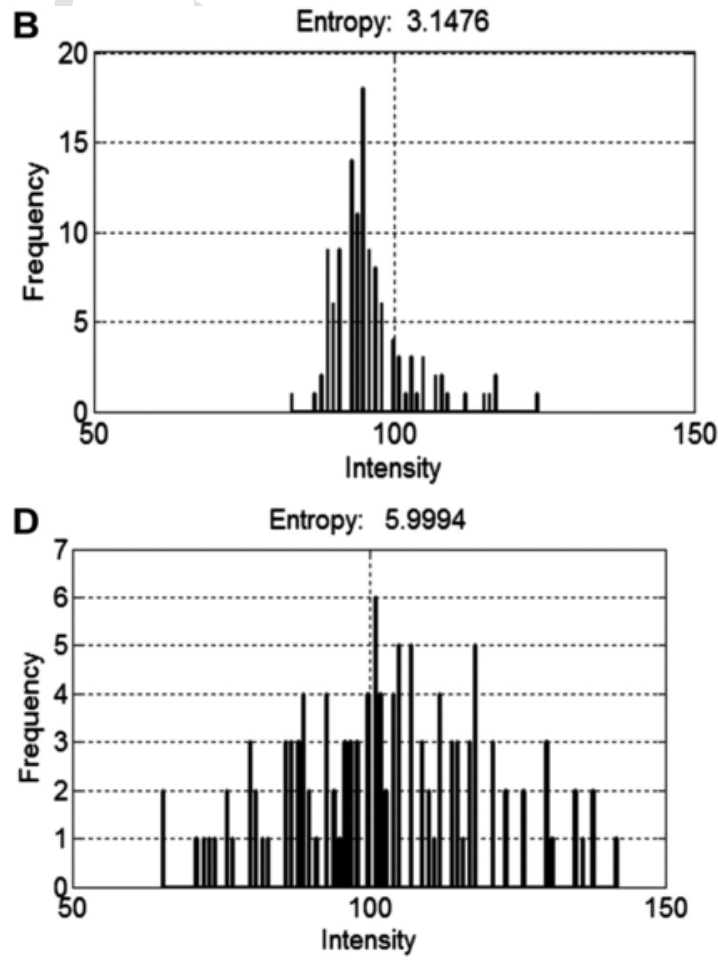

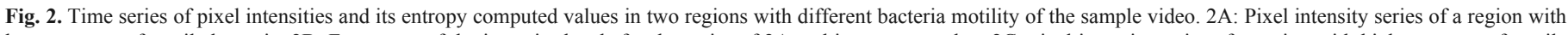

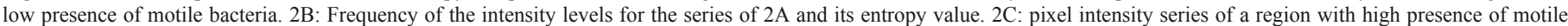
bacteria. 2D: Frequency of the intensity levels for the region of $2 \mathrm{C}$ and its entropy value. 
Fig $2 \mathrm{~A}$ it is shown the pixel intensity series of a region with low presence of bacteria. The histogram of the intensity levels is shown in Fig $2 \mathrm{~B}$ and its entropy value. In Fig $2 \mathrm{C}$ and $\mathrm{D}$, the graphs correspond to a pixel intensity sequence that belongs to an area of many motile bacteria. It is remarkable that the value of entropy in the region of higher motility is greater than the entropy value in the zone of lower motility.

The efficiency of the descriptor was evaluated with the Receiver Operating Characteristic (ROC) (Fawcett, 2004). We segmented regions on different images as high and low bacterial motility, determining a set of values of labeled entropies. Area Under the Curve (AUC) was used as measure of quality.

\subsection{The population motility index}

A segmentation of pseudo color images was done to obtain an index of bacterial population motility as a function of the distance from the plug. Morphological operations were applied on each frame with a rectangular structuring element of $3 \times 5$ pixels (Fig. 3). The image was binarized and the plug perimeter filled. Thus, two different regions were visualized. This mask is applied to the entropy image and the active region is divided into subzones ( $15 \mu \mathrm{m}$ in this case).

Given an entropy image, the following is computed:

a) $M(i, s)=\frac{1}{N} \sum_{n=1}^{N} E_{n}$

where $M$ is a motility index, $i$ denotes de \# assay, $i=0,1,2 \ldots 9$ in this case, where 0 refers to negative control assay, $s$ corresponds to an entropy image subzone, $s=1,2, \ldots T$ being $T$ the amount of subzones in image $i, n=1,2, \ldots n$ where $N$ is the number of the pixels in subzone $s$ of image $i$;

b) $M(i)_{\max }=\max (M(1), \ldots M(T))$

where $M(i)_{\max }$ is the maximum motility index presented for each assay;

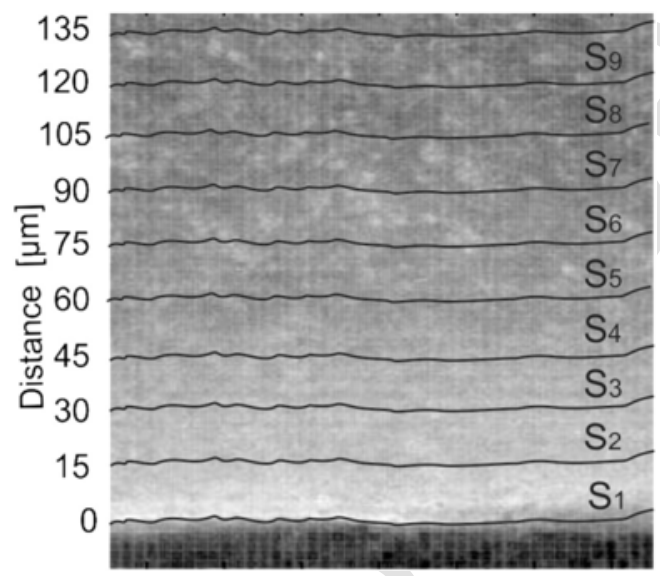

Fig. 3. Segmentation of time series images. Morphological operations were applied on each frame with a rectangular structuring element of $3 \times 5$ pixels. Each image was binarized and the plug perimeter filled. The active region was divided into subzones $(15 \mu \mathrm{m}$ in this case). c) $M(i)_{\min }=\min (M(1), \ldots M(T))$

where $M(i)_{\min }$ is the minimum motility index presented for each assay;

d) $R(i)=M(i)_{\max }-M(i)_{\min }$

where $R$ is the image range for each assay.

Then, the difference between the image range and the control image range was computed as:

e) $A(i)=R(i)-R(0)$

where $A$ is the attraction index. If $A>1$ then the chemotactic compound in $\# i$ assay behaves as an attractant; if $A<1$ then $i$ is a repellent compound. Absolute value of $A$ was used to compare intensity of the response among different assays.

Index values for each subzone were computed as the average over the replicates of each experiment.

\section{Results and discussion}

In this work we used the degree of motility as a way of scaling the chemotactic responses. Shannon's entropy applied to the changes in the intensity level of each pixel from the images time series showed to be a proper tool to estimate the dynamics generated by the movement of bacteria in a given area. As a reference, the Area Under the Curve (AUC), which is an indicator of the overall quality of the ROC curves, revealed that the entropy estimator has a value of 0.9946 . This showed its efficiency, as clearly exceed the classification by chance $(\mathrm{AUC}=0.5)$ considered as the lowest limit for its acceptance.

Previous reports on bacterial population chemotaxis detection with a video processing method measured the change in bacterial density at the detection area to distinguish attractant from repellent (Jeong et al., 2013) or the area covered by bacteria trough time (Nikata et al., 1992). These techniques could add errors due to the presence of non-motile microorganism or particles present in the chamber. The methodology proposed in this study cannot be influenced by non-motile bacteria or particles as the descriptor only estimate the level of entropy generated in each pixel by the objects (bacteria) moving in the assay.

Entropy color images of the studied assays allowed easily observing the temporal behavior of the bacterial population compared to the microscope B\&W images (Fig. 4). The presence of a middle-bacterial activity area (yellow) around the negative control plug (Fig 4, Negative plug B) could indicate certain bacterial attraction to the agar. However, the activity level is much lower than the response in positive chemotactic assays (Fig 4, Positive plug B). Chemotactic response was considered positive when the level of entropy in the area around the plug was higher than in the negative control test.

Pure hydrocarbons were also tested as chemoeffectors (Fig. 5). The processed images showed positive chemotaxis of $P$. aeruginosa strain $\mathrm{H}$ to glycerol, kerosene, 1-octene, 1 -dodecene, and $n$-hexadecane in decreasing order of the response. These results confirm the chemotactic response of Polycystis aeruginosa strain H towards kerosene, 1 -dodecene and $n$-hexadecane previously mention by Nisenbaum et al. $(2013,2014)$. The motility of the bacterial clusters around the plug for 1-decene, 1-nonene and 1-undecene were lower than for the negative plug (showed in Fig. 4) and decreased over 
Positive plug

A
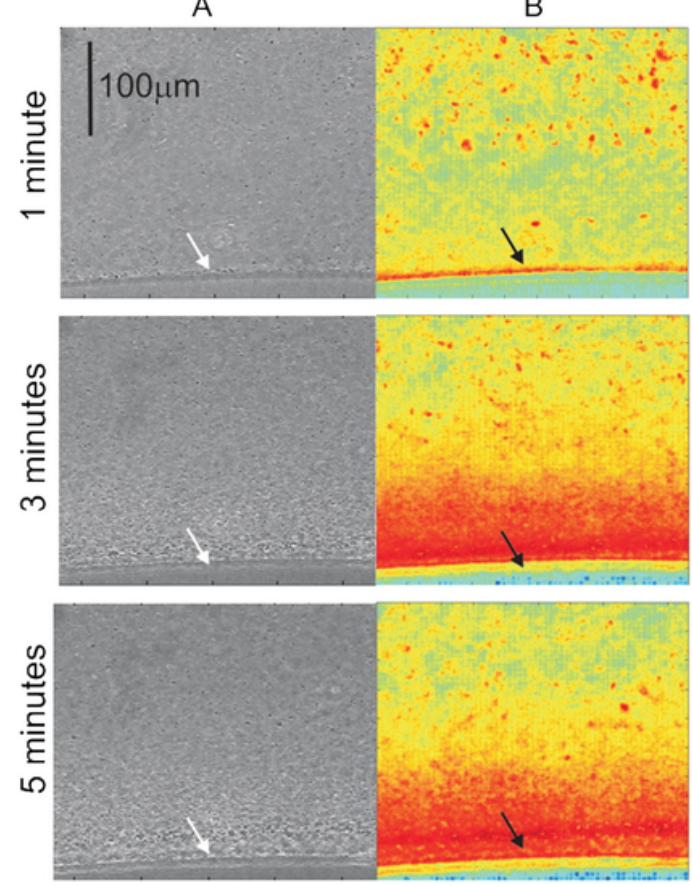

Negative plug

A $B$
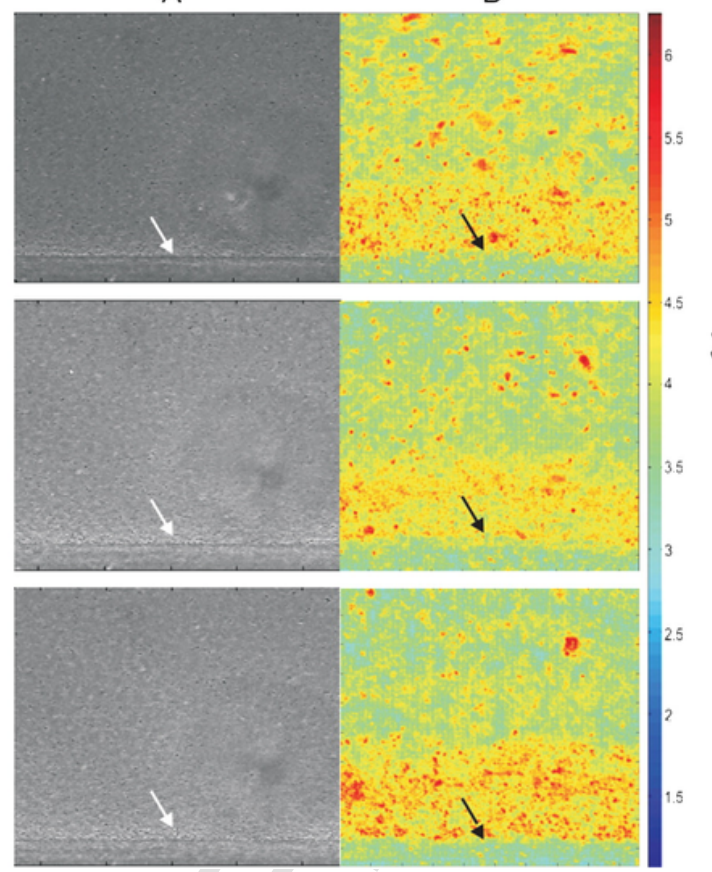

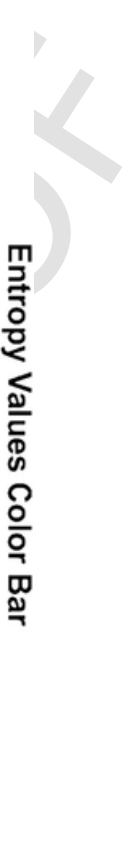

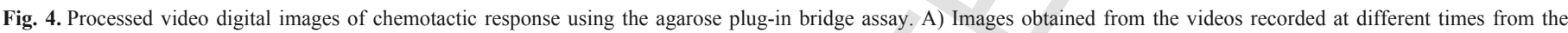

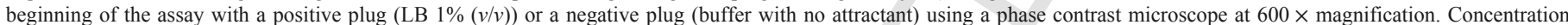

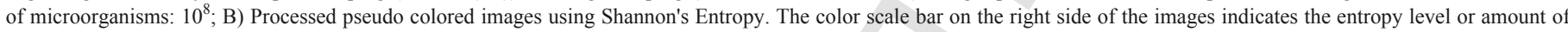

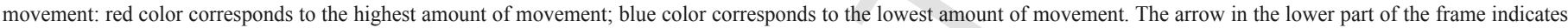
the agarose plug. (For interpretation of the references to color in this figure legend, the reader is referred to the web version of this article.)

time, which indicates a negative chemotactic response. The 1-decene assay presented fewer entropy at $1 \mathrm{~min}$ than the rest of the negative chemotaxis assays, thus we could infer the fastest bacterial response away from the plug.

The decrease or increase in the level of entropy around the plug over time in the processed images allowed to discriminate between positive and negative chemotactic responses. The intensity of the colors around the plug allowed the comparison in chemotaxis responses between different chemoeffectors. Thus, the processed images provided easier identification and analysis of the accumulation of bacteria around the plug than previous reports on chemotactic response using the agarose in-plug assay (Parales et al., 2001; Lanfranconi et al., 2003).

The majority of the reported chemotactic methods are focused on the qualitative response, but a quantitative criterion is needed to characterize the degree of chemotaxis when the response is not so clear. In this work, we propose a particular motility index $(M(i, s)$, Eq. (2)) to indicate the degree of motility in a given area. The index was calculated and defined as the average entropy in a particular zone of the image.

In this work, the spatial evolution of motile clusters was evaluated at $5 \mathrm{~min}$ from starting the assay (Fig. 6). A plot was done applying $M(i, s)$ to different subareas of the active images (close to the plug), versus the distance from the plug (Fig. 5). A decrease in $M(i, s)$, was observed with increasing distance from the plug for all the hydrocarbons and controls tested.

Table 1 shows the temporal evolution of the motility index $(M(i))$ in the adjacent area of the plug at 1,3 and $5 \mathrm{~min}$ from the beginning of the assay for all tested hydrocarbons and controls. A positive $M(i)$ value for each time indicates that the disordered movement in that area, generated by motile cells, is higher than for the negative assay. The opposite happens when the $M(i)$ value is negative and the response is seen as a temporal bacterial retraction (back motion) after sensing the chemotaxis-inducer. For all the attractants, the strongest chemotactic response (highest entropy peak) in the area next to the plug is presented after 3 min from the beginning of the assay, except for 1-dodecene which presented the maximum value at $5 \mathrm{~min}$ (Fig. 5 and Table 1). The strongest motility index (highest entropy peak) next to the plug was detected in the assay with kerosene, followed by 1-octene and glycerol, with higher motile index than LB, 1-dodecene, n-hexadecane and 1-nonene, in decreasing order. On the other hand, the assays with 1-decene, 1-undecene and 1-nonene as chemoeffectors presented negative $M(i)$ values, at a declining sequence. The negative motile index assays showed a decrease of motility over time next to the plug. For these chemorepellents the strongest negative response occurred at $5 \mathrm{~min}$ of the assay.

The motility index can be determined at different times and different zones of the assay to compare the response of different chemoeffectors as the research requires. Also, the segmented areas in the images for determining the entropy indexes could be chosen as needed. This index could act as a parameter to determine the significance of chemotaxis in the biodegradation of each chemoeffector.

An Attraction Index $(A(i)$, Eq. (6)) was also presented to determine the chemoeffector as attractant or repellent and to compare the intensity of the bacterial population response (Table 2). This analysis confirmed the responses observed from the processed images (Figs. 4 and 5) where the response towards kerosene and glycerol was closest to the response to LB, and was higher than octane $>n$-hexadecane $>1$-dodecene. The others chemoeffectors act as repellents in this decreasing way: 1 -undecene $>1$-decene $>1$-nonene. 

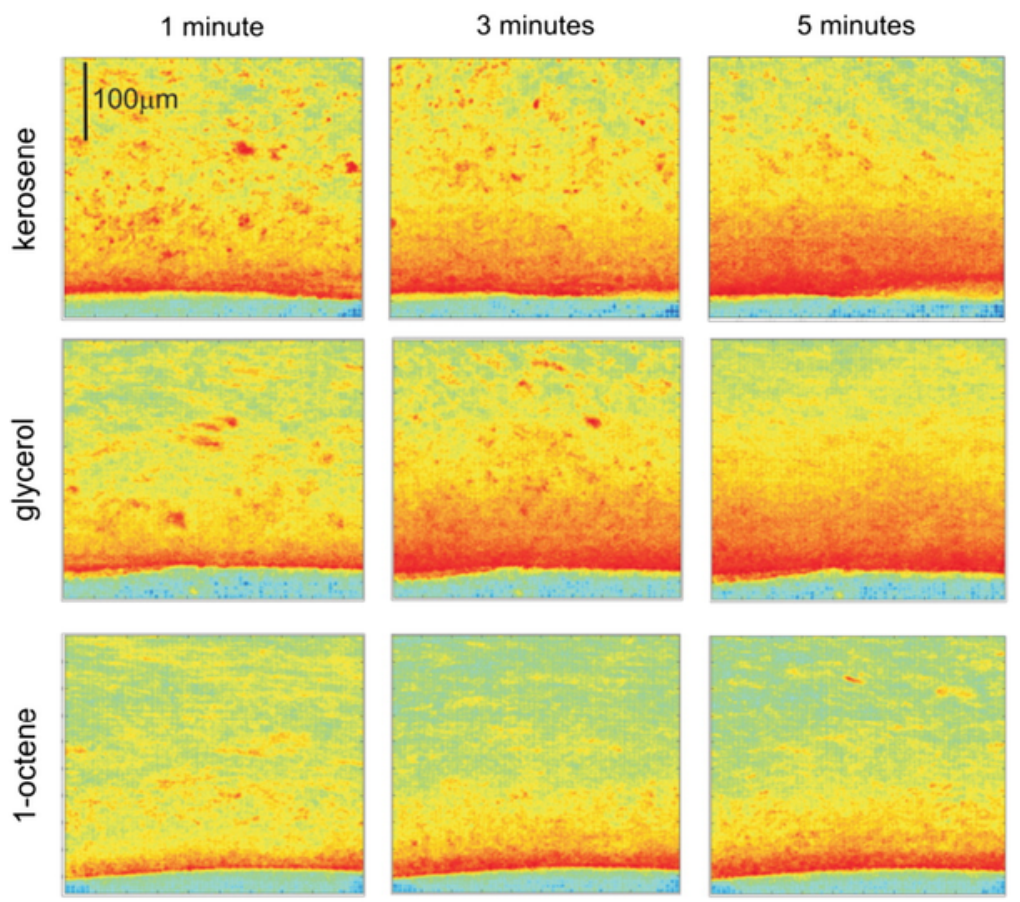

5.5
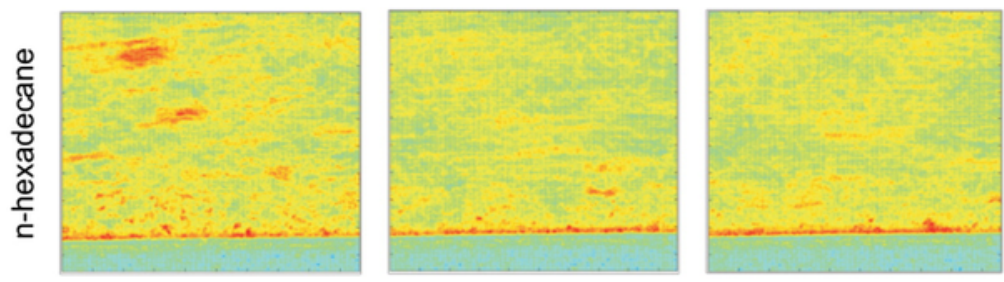

5
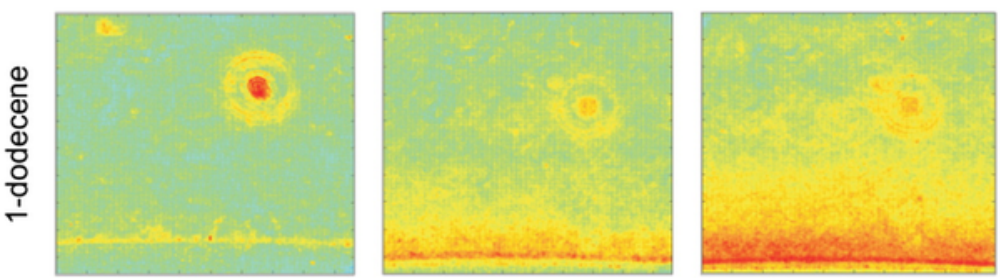

4.5
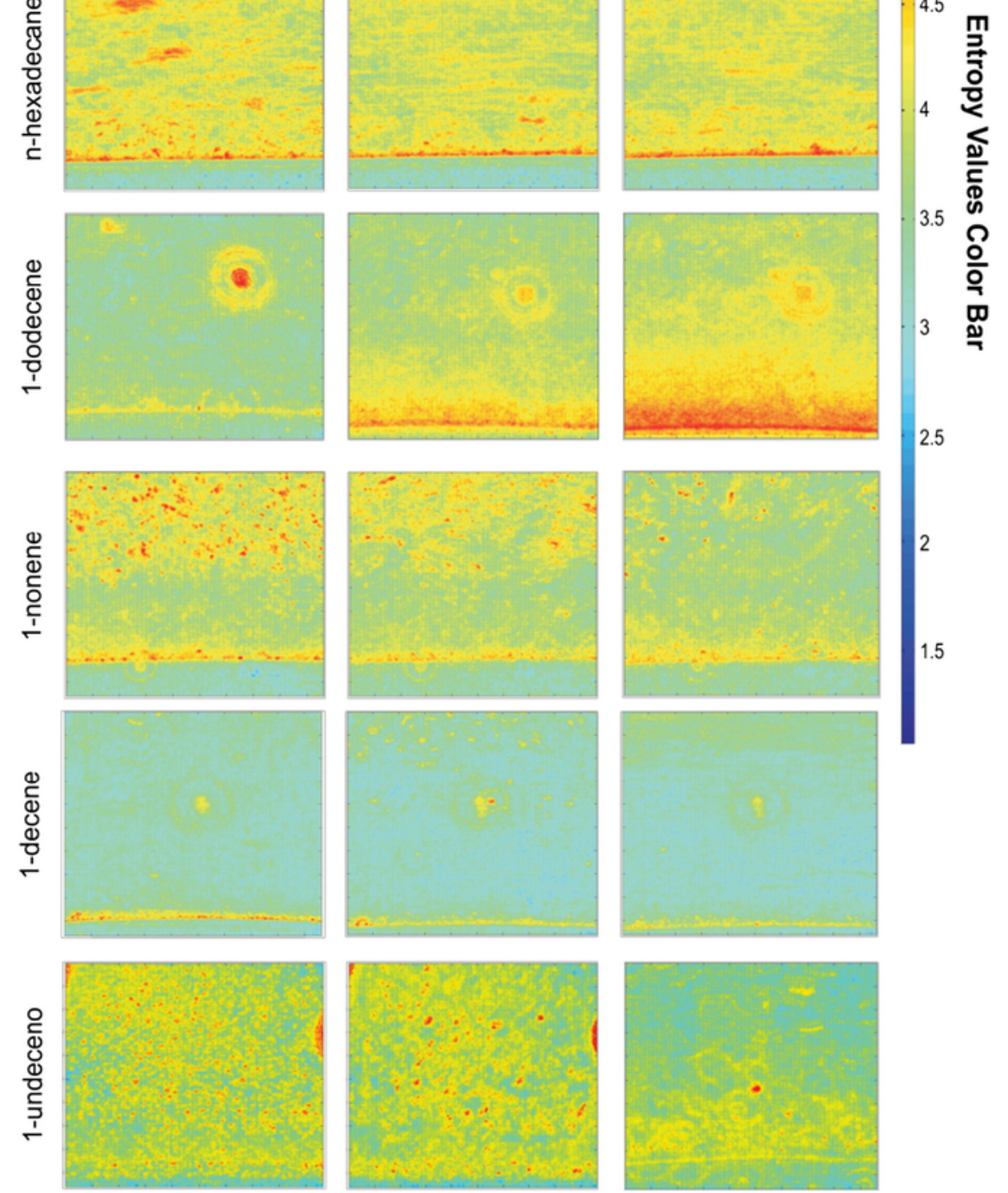
With the Motility Index and Attraction Index provided, this video processing method allowed obtaining quantitative information of the dynamic changes in space and time from a traditional qualitative assay.

The agarose-in plug assay analyzed with the video processed images method described above, provides a simple and reproducible way to perform the quantitative and qualitative analysis of bacterial chemotaxis. This methodology has full compatibility with a conventional laboratory infrastructure and in combination with an optical microscope and a computer it can be immediately used in microbiology laboratories in both academia and industry.

The results presented underscore the advantages of using imagebased analysis to quantify multiple parameters as grade of motility from low cost assays. Although this method was used with the wellknown agarose-in plug bridge method, could be broadly used for other microbial chemotactic assays which involve the use of an optic microscope. We can mention the drop plate assay and the chemical-in-plug method (Arora et al., 2015), chemical-in capillary method and chemical-in pond method (Tso and Adler, 1974) that are limited due to the low sensitivity or for the high concentration of bacteria needed to be detected. The method presented in this work allows working with low cell concentration mainly due to the high selectivity of the processing which only uses movement objects in the frame. This is an advantage when researchers work with xenobiotic compounds which minimize the bacterial concentration (Nisenbaum et al., 2013, 2014). Additionally, working with low bacterial concentrations is advantageous because metabolism of a chemoeffector is slow enough that chemoeffector gradients are not affected by metabolism.

\section{Conclusions}

In this work we proposed a new methodology based on video processes analysis to compare and quantify the chemotactic responses towards different attractants using the simple and low cost traditional agarose-in plug bridge assay (Yu and Alam, 1997). This well-known method has been a useful tool for obtaining qualitative information in bacterial chemotactic responses. A network of spatial and temporal bacterial dynamic information was added to the assay with the video processing method presented in this work. The Shannon entropy was an efficient descriptor of bacterial chemotactic processes. We have shown the efficiency of this technique for comparison of bacterial population behavior towards or away from diverse attractants. Video sequences processing allows discriminating time and space evolution of bacterial population movement and obtaining numerical results as Motility Index and Attraction Index that allow the quantification of the response. This methodology could be broadly used for other microbial chemotactic assays which involve the use of a microscope couple to a computing device.

\section{Acknowledgements}

We thank National University of Mar del Plata, where this research took place. We also thank CIC and CONICET for the fellowships, grants and salaries, S. Murialdo is a researcher of CIC. This work was supported by National University of Mar del Plata (15G/426 ING432/ 15 and 15/G433 ING439/15) and CONICET (PICT 2014-1567).

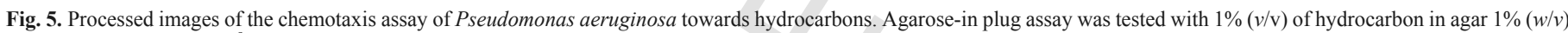

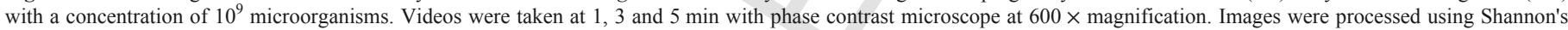

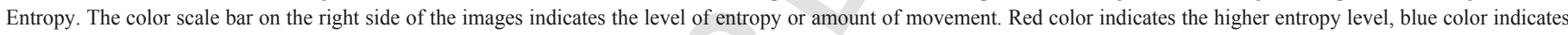

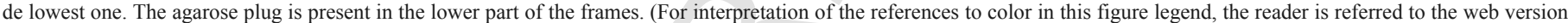
of this article.) 


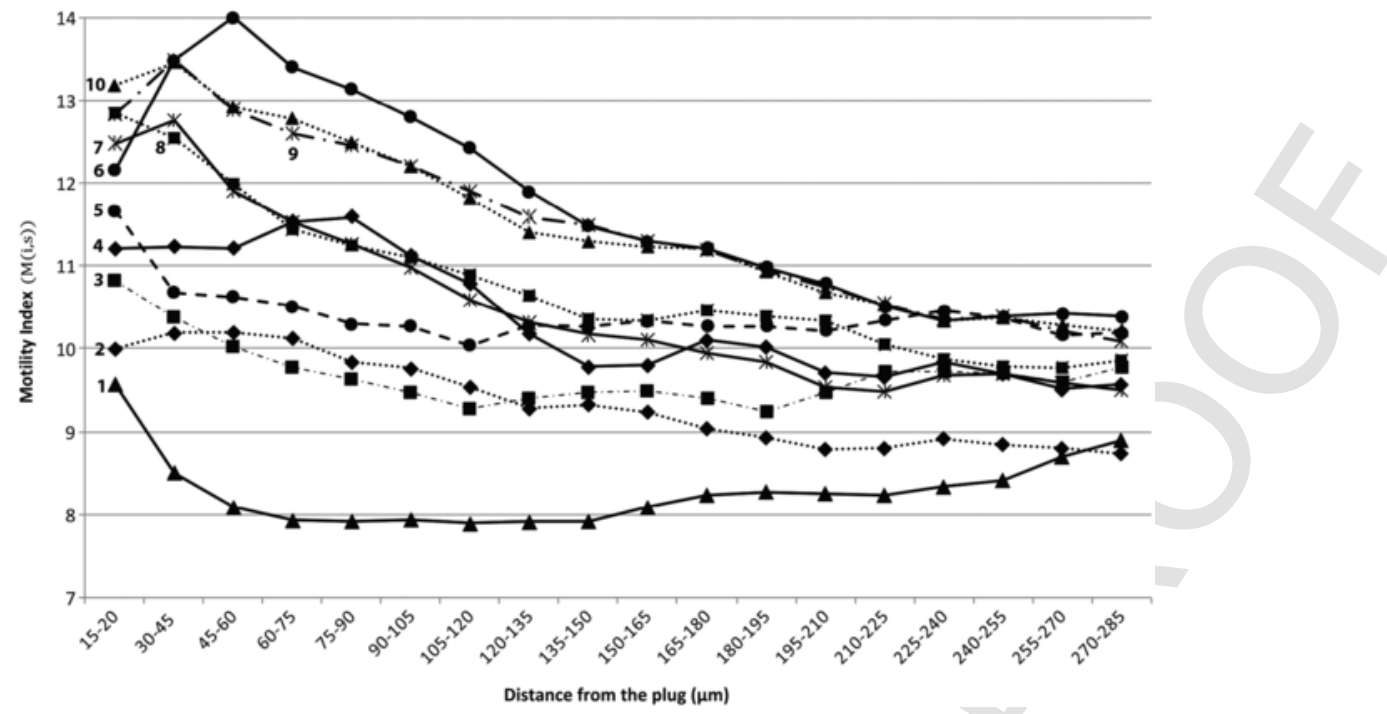

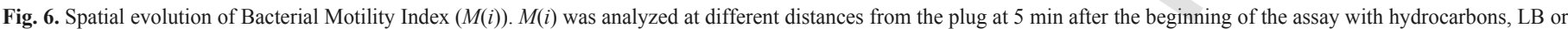
buffer as possible attractants. 1) 1-decene; 2) 1-undecene; 3) 1-nonene; 4) buffer (negative control); 5) n-hexadecane; 6) LB; 7) 1-octene; 8) 1-dodecene; 9) glycerol; 10) kerosene.

Table 1

Temporal evolution of Bacterial Motility Index. Bacterial motility index $(M(i))$ were determined as the average entropy assessed in the zone next to the plug $(15-20 \mu \mathrm{m})$ in each processed image at 1, 3 and $5 \mathrm{~min}$ after the beginning of the assay. Values obtained for the negative control plug in each time were substracted from the values of the tested chemoeffectors. A value of 0 indicates the absence of net response. \#: assay number.

\begin{tabular}{llccc}
\hline$\# i$ & Plug $(i)$ & \multicolumn{2}{c}{$M(i)$} & \\
\hline & & $1 \mathrm{~min}$ & $3 \mathrm{~min}$ & $5 \mathrm{~min}$ \\
\hline 0 & Negative control (no attractant) & 0 & 0 & 0 \\
1 & LB & 0.69 & 1.89 & 0.96 \\
2 & Kerosene & 1.69 & 2.81 & 1.98 \\
3 & Glycerol & 1.59 & 2.3 & 1.63 \\
4 & 1-Octene & 1.6 & 2.42 & 1.18 \\
5 & n-Hexadecane & 0.73 & 0.94 & 0.47 \\
6 & 1-Dodecene & -0.6 & 1.33 & 1.64 \\
7 & 1-Nonene & 0.44 & 0.3 & -0.38 \\
8 & 1-Decene & -0.37 & -0.84 & -1.64 \\
9 & 1-Undecene & -0.78 & -0.18 & -1.2 \\
\hline
\end{tabular}

Table 2

Assessment of positive or negative chemotactic response from Attraction Index $(A(i))$. From the processed images at $5 \mathrm{~min}$ from the beginning of the assay. $A(i)=R(i)-R(0)$, where $R(i)=M(i)_{\max }-M(i)_{\min }$ and $R(0)$ is the negative control range. $M(i)_{\max }$ : maximum motility index, $M(i)_{\min }$ : minimum motility index. $(+)$ : positive chemotaxis; $(-)$ : negative chemotaxis; 0: no response. \#: assay number.

\begin{tabular}{llllll}
\hline$\# i$ & Plug $(i)$ & $M(i) \max$ & $M(i)_{\min }$ & $A(i)$ & $\begin{array}{l}\text { Chemotactic } \\
\text { response }\end{array}$ \\
\hline 0 & $\begin{array}{l}\text { Negative control (no } \\
\text { attractant) }\end{array}$ & 11,59 & 9,12 & 0 & 0 \\
1 & LB & 14,00 & 8,39 & 3.14 & + \\
2 & Kerosene & 13,46 & 8,25 & 2.74 & + \\
3 & Glycerol & 13,48 & 8,30 & 2.71 & + \\
4 & 1-Octene & 12,76 & 8,38 & 1,91 & + \\
5 & n-Hexadecane & 11,67 & 8,54 & 0.66 & + \\
6 & 1-Dodecene & 12,84 & 9,77 & 0.60 & + \\
7 & 1-Nonene & 10,82 & 8,89 & -0.54 & - \\
7 & 1-Decene & 9,57 & 7,89 & -0.79 & - \\
9 & 1-Undecene & 10,20 & 8,74 & -1.01 & - \\
\hline
\end{tabular}

\section{References}

Adler, J., 1966. Chemotaxis in bacteria. Science 133, 708-716. http://dx.doi.org/10. $1002 /$ jss.400040302.

Adler, J., 1969. Chemoreceptors in bacteria. Science 166, 1588-1597. http://dx.doi. org/10.1126/science.166.3913.1588.

Adler, J., 1973. A method for measuring chemotaxis and use of the method to determine optimum conditions for chemotaxis by Escherichia coli. J. Gen. Microbiol. 74, 77-91. http://dx.doi.org/10.1099/00221287-74-1-77.

Arora, P.K., Jeong, M.J., Bae, H., 2015. Chemotaxis away from 4-chloro-2-nitrophenol, 4-nitrophenol, and 2,6-dichloro-4-nitrophenol by Bacillus subtilis PA-2. J. Chem, Article ID 296231http://dx.doi.org/10.1155/2015/296231 (4 p). (Hindawi Publishing Corporation).

Beck, J., Schwanghart, W., 2010. Comparing measures of species diversity from incomplete inventories: an update. Methods Ecol. Evol. Vol. 1 (Issue 1), 38-44. http: //dx.doi.org/10.1111/j.2041-210X.2009.00003.x.

Berg, H.C., 1993. Random Walks in Biology. Princeton University Press, Princeton, N.J. (ISBN: 9780691000640).

Berg, H.C., Tedesco, P.M., 1975. Transient response to chemotactic stimuli in Escherichia coli. Proc. Natl. Acad. Sci. U. S. A. 72, 3235-3239. http://dx.doi.org/10. 1073/pnas.72.8.3235.

Berg, H.C., Turner, L., 1990. Chemotaxis of bacteria in glass capillary arrays. Escherichia coli, motility, microchannel plate, and light scattering. Biophys. J. 58, 919-930. http://dx.doi.org/10.1016/S0006-3495(90)82436-X.

Bosma, T.N.P., Schnoor, J.L., Schraa, G., Zehnder, A.J.B., 1988. Simulation model for biotransformation of xenobiotics and chemotaxis in soil columns. J. Contam. Hydrol. 2, 225-235. http://dx.doi.org/10.1016/0169-7722(88)90023-X.

Boudko, D., Yu, H.S., Ruiz, M., Hou, S., Alam, M., 2003. A time-lapse capillary assay to study aerotaxis in the archaeon Halobacterium salinarum. J. Microbiol. Methods 53, 123-126. http://dx.doi.org/10.1016/S0167-7012(02)00227-0.

Cluzel, P., Surette, M., Leibler, S., 2000. An ultrasensitive bacterial motor revealed by monitoring signaling proteins in single cells. Science 287, 1652-1655. http://dx. doi.org/10.1126/science.287.5458.1652.

Dahlquist, F.W., Lovely, P., Koshland, D.E., 1972. Quantitative analysis of bacterial migration in chemotaxis. Nat. New Biol. 236, 120-123. http://dx.doi.org/10.1038/ newbio236120a0.

Di Leonardo, R., Dell'Arciprete, D., Angelani, L., Lebba, V., 2011. Swimming with an image. Phys. Rev. Lett. 106, 038101. http://dx.doi.org/10.1103/PhysRevLett.106. 038101.

Emerson, D., Worden, R.M., Breznak, J.A., 1994. A diffusion gradient chamber for studying microbial behavior and separating microorganisms. Appl. Environ. Microbiol. 60, 1269-1278.

Fawcett, T., 2004. ROC Graphs: notes and practical considerations for researchers. In: Technical Report. HP Laboratories, Palo Alto, USA.

Fuhrman, S., Cunningham, M.J., Wen, X., Zweiger, G., Seilhamer, J.J., Somogyi, R., 2000. The application of Shannon entropu in the identification of putative drug targets. Biosystems 55, 5-14. http://dx.doi.org/10.1016/S0303-2647(99)00077-5.

Gestwicki, J.E., Kiessling, L.L., 2002. Inter-receptor communication through arrays of bacterial chemoreceptors. Nature 415, 81-84. http://dx.doi.org/10.1038/415081a. 
Harwood, C.S., Fosnaugh, K., Dispensa, M., 1989. Flagellation of pseudomonas putida and analysis of its motile behavior. J. Bacteriol. 171, 4063-4066.

Jasuja, R., Lin, Y., Trentham, D.R., Khan, S., 1999. Response tuning in bacterial chemotaxis. Proc. Natl. Acad. Sci. U. S. A. 96, 11346-11351. http://dx.doi.org/10. 1073/pnas.96.20.11346.

Jeong, H.H., Lee, S.H., Lee, C.S., 2013. Pump-less static microfluidic device for analysis of chemotaxis of pseudomonas aeruginosa using wetting and capillary action. Biosens. Bioelectron. 47, 278-284. http://dx.doi.org/10.1016/j.bios.2013.03. 031.

Kapur, J.N., 1989. On the concept of useful information. J. Org. Behav. Stat., vol. $2,147-162$.

Krell, T., Lacal, J., Reyes Darias, J.A., Jimenez-Sanchez, C., Sungthong, R., OrtegaCalvo, J.J., 2013. Bioavailability of pollutants and chemotaxis. Curr. Opin. Biotechnol. 24, 451-456. http://dx.doi.org/10.1016/j.copbio.2012.08.011.

Lanfranconi, M.P., Alvarez, H.M., Studdert, C.A., 2003. A strain isolated from gas oilcontaminated soil displays chemotaxis towards gas oil and hexadecane. Environ. Microbiol. 5, 1002-1008. http://dx.doi.org/10.1046/j.1462-2920.2003.00507.x.

Larsen, S.H., Reader, R.W., Kort, E.N., Tso, W.W., Adler, J., 1974. Change in direction of flagellar rotation is the basis of the chemotactic response. Nature 249, 74-77. http://dx.doi.org/10.1038/249074a0.

Lauga, E., Powers, T.R., 2009. The hydrodynamics of swimming microorganisms. Rep. Prog. Phys. 72 (096601), 36. http://dx.doi.org/10.1088/0034-4885/72/9/ 096601.

Law, A.M.J., Aitken, M.D., 2005. Continuous-flow capillary assay for measuring bacterial chemotaxis. Appl. Environ. Microbiol. 71, 3137-3143. http://dx.doi.org/10. 1128/AEM.71.6.3137-3143.2005.

Lewus, P., Ford, R.M., 2001. Quantification of random motility and chemotaxis bacterial transport coefficients using individual-cell and population-scale assays. Biotechnol. Bioeng. 75, 292-304. http://dx.doi.org/10.1002/bit.10021.

Li, J., Go, A.C., Ward, M.J., Ottemann, K.M., 2010. The chemical in-plug bacterial chemotaxis assay is prone to false positive responses. BMC Research Notes 3 (article 77)http://dx.doi.org/10.1186/1756-0500-3-77.

Mao, H., Cremer, P.S., Manson, M.D., 2003. A sensitive, versatile microfluidic assay for bacterial chemotaxis. Proc. Natl. Acad. Sci. U. S. A. 100, 5449-5454. http://dx doi.org/10.1073/pnas.093125810038.

Marx, R.B., Aitken, M.D., 2000. A material-balance approach for modeling bacterial chemotaxis to a consumable substrate in the capillary assay. Biotechnol. Bioeng. 68, 308-315. http://dx.doi.org/10.1002/(SICI)1097-0290(20000505)68 $3<308:$ :AID-BIT9>3.0.CO;2-N.

Meyvantsson, I., Vu, E., Lamers, C., Echeverria, D., Worzella, T., Echeverria, V., et al., 2011. Image-based analysis of primary human neutrophil chemotaxis in an automated direct-viewing assay. J. Immunol. Methods 4, 70-77. http://dx.doi.org/ 10.1016/j.jim.2010.12.017.

Murialdo, S.E., Fenoglio, R., Haure, P.M., González, J.F., 2003. Degradation of phenol and chlorophenols by mixed and pure cultures. Water SA 29, 457-463. http://dx doi.org/10.4314/wsa.v29i4.5053

Nikata, T., Sumida, K., Kato, J., Ohtake, H., 1992. Rapid method for analyzing bacterial behavioral responses to chemical stimuli. Appl. Environ. Microbiol. 58, 2250-2254.

Nisenbaum, M., Bouchet, A., Guzmán, M., González, J.F., Sendra, G.H., Pastore, J., Trivi, M., Murialdo, S.E., 2014. Dynamic laser speckle and fuzzy mathematical morphology applied to studies of chemotaxis towards hydrocarbons. Int J Environ Health 7, 58-69. http://dx.doi.org/10.1504/IJENVH.2014.060121.

Nisenbaum, M., Sendra, G.H., Cerdá, G., Scagliola, M., Rabal, H., González, J.F., Murialdo, S.E., 2013. Hydrocarbon biodegradation and dynamic laser speckle for detecting chemotactic responses at low bacterial concentration. J. Environ. Sci. 25, 613-625. http://dx.doi.org/10.1016/S1001-0742(12)60020-5.
Ortega-Calvo, J.J., Marchenko, A.I., Borobyov, A.I., Borovick, R.V., 2003. Chemotaxis in polycyclic aromatic hydrocarbon-degrading bacteria isolated from coal tarand oil-polluted rhizospheres. FEMS Microbiol. Ecol. 44, 373-381. http://dx.doi. org/10.1016/S0168-6496(03)00092-8.

Parales, R.E., Ditty, J.L., Harwood, C.S., 2001. Toluene-degrading bacteria are chemotactic towards the environmental pollutants benzene, toluene, and trichloroethylene. Appl. Environ. Microbiol. 66, 4098-4104. http://dx.doi.org/10.1128/AEM.66. 9.4098-4104.2000.

Paul, D., Singh, R., Jain, R.K., 2006. Chemotaxis of Ralstonia sp. SJ98 towards p-nitrophenol in soil. Environ. Microbiol. 8, 1797-1804. http://dx.doi.org/10.1111/j. 1462-2920.2006.01064.x.

Pedit, J.A., Marx, R.B., Miller, C.T., Aitken, M.D., 2002. Quantitative analysis of experiments on bacterial chemotaxis to naphthalene. Biotechnol. Bioeng. 78, 626-634. http://dx.doi.org/10.1002/bit.10244.

Phillips, B.R., Quinn, J.A., Goldfine, H., 1994. Random motility of swimming bacteria: single cells compared to cell populations. AIChE J 40, 334-348. http://dx.doi org/10.1002/aic.690400212.

Rubik, B.A., Koshland, D.E., 1978. Potentiation, desensitization, and inversion of response in bacterial sensing of chemical stimuli. Proc. Natl. Acad. Sci. U. S. A. 75, 2820-2824. http://dx.doi.org/10.1073/pnas.75.6.2820.

Schmidt, S., Widman, M.T., Worden, R.M., 1997. A laser-diffraction capillary assay to measure random motility in bacteria. Biotechnol. Tech. 11, 423-426. http://dx.doi. org/10.1023/A:10184250081.

Segall, J.E., Block, S.M., Berg, H.C., 1986. Temporal comparisons in bacterial chemotaxis. Proc. Natl. Acad. Sci. U. S. A. 83, 8987-8991. http://dx.doi.org/10.1073/ pnas.83.23.8987.

Shannon, C.E., 1948. A mathematical theory of communication. Bell System Tech J 27 (379-423), 623-656. http://dx.doi.org/10.1002/j.1538-7305.1948.tb00917.x.

Spudich, J.L., Koshland, D.E., 1975. Quantitation of the sensory response in bacterial chemotaxis. Proc. Natl. Acad. Sci. U. S. A. 72, 710-713. http://dx.doi.org/10.1073/ pnas.72.2.710

Taylor, B.L., Koshland Jr., D.E., 1974. Reversal of flagellar rotation in monotrichous and peritrichous bacteria: generation of changes in direction. Bacteriol $119,640-642$

Thar, R., Fenchel, T., 2001. True chemotaxis in oxygen gradients of the sulfur-oxidizing bacterium Thiovulum majus. Appl. Environ. Microbiol. 67, 3299-3303. http:// dx.doi.org/10.1128/AEM.67.7.3299-3303.2001.

Thar, R., Ku“hl, M., 2003. Bacteria are not too small for spatial sensing of chemical gradients: an experimental evidence. Proc. Natl. Acad. Sci. U. S A. 100, 5748-5753. http://dx.doi.org/10.1128/AEM.67.7.3299-3303.2001.

Tsang, N., Macnab, R., Koshland, D.E., 1973. Common mechanism for repellents and attractants in bacterial chemotaxis. Science 181, 60-63. http://dx.doi.org/10.1126/ science.181.4094.60

Tso, W.W., Adler, J., 1974. Negative chemotaxis in Escherichia coli. J. Bacteriol. 118, 560-576

Tu, Y., 2013. Quantitative modeling of bacterial chemotaxis: signal amplification and accurate adaptation. Annu. Rev. Biophys. 42, 337-359. http://dx.doi.org/10.1146/ annurev-biophys-083012-130358.

Vladimirov, N., Lovdok, L., Lebiedz, D., Sourjik, V., 2008. Dependence of bacterial chemotaxis on gradient shape and adaptation rate. PLoS Comput. Biol. 4, e1000242http://dx.doi.org/10.1371/journal.pcbi.1000242.

Yu, H.S., Alam, M., 1997. An agarose-in-plug bridge method to study chemotaxis in the archaeon Halobacterium salinarum. FEMS Microbiol. Lett. 156, 265-269. http: //dx.doi.org/10.1111/j.1574-6968.1997.tb12738.x.

Zaval'skii, L.Y., Marchenko, A.I., Borovik, R.V., 2003. The study of bacterial chemotaxis to naphthalene. Microbiologica 72,363-368. http://dx.doi.org/10.1023/A: 1024216503463 . 